\title{
HABERMAS E A PÓS-MODERNIDADE
}

Rosa Maria F. Martini*

SÍNTESE - Este artigo resume os pontos básicos que caracterizam Habermas como um critico da modernidade e, conseqüentemente, como um filósofo pós-moderno.
ABSTRACT - This article summarizes the main issues that identify Habermas as a critical philosopher of modern times and consequently as a postmodern philosopher.

Habermas faz filosofia reconstruindo os caminhos da racionalidade, apostando na capacidade de aprender da espécie humana. Retomando a tradição iluminista atualiza o passado para tornar presente as possibilidades de correção dos rumos da racionalidade na pós-modernidade, numa configuração ética do seu próprio projeto.

Com essa forma de fazer filosofia, Habermas assume a própria tarefa articuladora das expressões culturais, tarefa própria da filosofia, enquanto intérprete da formação da espécie humana em processo de contínua aprendizagem.

Assumindo o discurso da modernidade, Habermas não se coloca fora dela como um observador imparcial, mas como um participante que dialoga, critica, transforma, reconstrói ao identificar déficits de racionalidade e novas possibilidades produtivas ou provocadoras.

É na crítica hegeliana ao projeto transcendental kantiano que Habermas percebe o desenrolar do Discurso Filosófico da Modernidade.

Hegel é apontado por Habermas como o último dos filósofos, porque reconheceu como tarefa da filosofia traduzir seu próprio tempo em pensamento, enquanto síntese final da cultura.

A filosofia hegeliana se realiza como um diagnóstico de uma época em que a razão é vista como um poder unificador, capaz de recompor as bipartições, instauradas pela subjetividade transcendental, demarcadora formal dos critérios para separação das esferas culturais da ciência, do direito, da moral e da arte.

Segundo Habermas, Hegel, ao tornar visivel a relação entre modernidade, racionalidade e consciência do tempo, adota dois caminhos críticos.

O primeiro seguido na juventude se refere a uma maiêutica da vida oprimida pelos poderes do Estado e da Religião - é um caminho ético e político.

O segundo caminho, o da maturidade, faz a critica do idealismo subjetivo de Kant e Fichte. Neste segundo momento, há uma desagudização da crítica. Após o

* Universidade Federal do Rio Grande do Sul, UFRGS.

\begin{tabular}{|l|l|l|l|l|l|} 
VERITAS & Por to Alegre & v. 41 & $\mathrm{n}^{9} 162$ & Junho 1996 & p. 307-312 \\
\hline
\end{tabular}


espirito ter penetrado na realidade e ter se tornado objetivo, Hegel, segundo Habermas, dispensa a filosofia de confrontar a existência dilacerada da vida social e política com o seu próprio conceito. Para Habermas Hegel destrói a relação entre modernidade, racionalidade e consciência de tempo, porque a racionalidade, dilatada até o espírito absoluto, neutraliza as condições sob as quais a modernidade adquiriu a consciência de si mesma.

Depois de Hegel, o próprio conceito de razão torna-se criticável, porque não mais se aceita que a razão apoiada no princípio da subjetividade denuncie a alienação para impor seu dominio sobre a própria racionalidade.

As críticas pós-hegelianas que dão continuidade ao discurso da modernidade vão em três direções, segundo Habermas:

19. A que dá continuidade ao discurso hegeliano, numa atitude conservadora que se rende à racionalidade meio-fim, transformada em modernização social e no conjunto de categorias que configuram apenas uma crítica da razão.

$2^{\mathrm{a}}$. A crítica progressista que dá um significado emancipatório a uma racionalidade histórica, finita, imersa na prática e na crítica das ideologias que alienam o homem, voltada para a esperança de realizar a restauração de uma totalidade ética.

3a. Como uma terceira resposta ao problema da modernidade surge a crítica de Nietzsche com uma teoria do poder, como crítica emancipadora da razão que se coloca a si própria fora do horizonte da razão.

A dominação niilista da razão é concebida como expressão e resultado de uma perversão da vontade de poder. Segundo Habermas, a vontade de poder em Nietzsche é ainda uma versão metafísica do princípio dionisíaco, em que o niilismo, reinante no presente, indica o distanciamento dos deuses e anuncia a proximidade do ausente. A arte dá acesso ao dionisíaco a partir de uma fusão com a natureza interior e exterior. Com Nietzsche a crítica da modernidade renuncia, pela primeira vez, ao seu conteúdo emancipatório. A razão subjetivada se enfrenta com o seu outro.

Habermas vê nestas três atitudes de crítica a Hegel três formas de dar continuidade ao discurso da modernidade. Por outro lado, elas trazem três questões básicas. São elas:

$1^{a}$. ultrapassagem crítica do paradigma da consciência ou da subjetividade;

$2^{\mathrm{a}}$. discussão da posição do intelectual no contexto do discurso da modernidade;

3a. responsabilidade pela continuidade ou descontinuidade histórica decorrente da crítica à própria modernidade.

No Discurso Filosófico da Modernidade, Habermas verifica como para realizar a crítica à subjetividade da consciência transcendental Marx transforma o conceito de reflexão no conceito de produção, bem como o conceito de autoconsciência em trabalho.

Segundo Habermas, a filosofia da práxis permanece uma variante da filosofia do sujeito, pois mantém a racionalidade orientada para os fins do sujeito atuante. A necessidade de auto-objetivação está radicada também na estrutura da auto-exteriorização, do mesmo modo que na estrutura da auto-referência da consciência.

Habermas pergunta então o que a filosofia da práxis teria para se contrapor à razão instrumental de uma racionalidade teleológica, estendida para o plano da to- 
talidade social, quando ela tem de se entender a si própria em termos materialistas, como parte integrante e resultado de um contexto reificado, quando a pressão para a objetivação se faz sentir, no mais profundo da razão que critica.

O protesto com relação aos excessos da razão instrumental do Marxismo aparece na Dialética Negativa de Adorno (1985) como final da trajetória iluminista. A razão transforma-se em mito e a arte torna-se o único refúgio da razão crítica, face a crescente instrumentalização do mundo. Habermas considera Adorno e Horkeimer precursores da critica radical da modernidade, presente em Bataille, Foucault e Derrida, destacando, porém, que Adorno se mantém fiel ao impulso filosófico, não se furtando à estrutura paradoxal de um pensar da crítica totalizada.

Através das restrições, claramente expressas por Habermas, quanto às ligações de Heidegger com o Nazismo, é grande a influência deste filósofo no pensamento de Habermas, que o apresenta como uma forma de filosofar que supera 0 paradigma da subjetividade. Segundo Habermas, Heidegger domina o pensamento pós-moderno por uma superação imanente da metafísica, chegando a uma filosofia da origem temporalizada.

A filosofia crítica dos pós-hegelianos enfraquecera a filosofia. Para Habermas, Heidegger restitui à filosofia o poder que ela havia perdido. Seu conceito de mundo da vida como estrutura de pré-compreensão ontológica, condicionante de um horizonte que predetermina o sentido do ente, é central para a organização do paradigma de trabalho habermasiano mundo da vida e sistema.

Habermas resume três estratégias conceituais da filosofia heideggeriana: Heidegger faz a junção da filosofia transcendental com a ontologia de modo a poder distinguir a analítica existencial como ontologia fundamental; além disso, atribui à fenomenologia o sentido de uma hermenêutica ontológica de modo a poder realizar a ontologia fundamental como hermenêutica existencial e, finalmente, ocupa a hermenêutica existencial com motivos filosóficos existenciais para ainda poder integrar a empresa da ontologia fundamental no contexto dos interesses, antes depreciados como meramente ônticos.

Habermas assinala a virada ontológica de Heidegger como uma ultrapassagem do paradigma da consciência por meio da radicalização da filosofia transcendental. Em lugar da auto-reflexão da fenomenologia husserliana, coloca-se a interpretação de uma compreensão pré-ontológica do ser e com ela a explicação das relações de sentido, nas quais a existência quotidiana já se encontra situada. No lugar da subjetividade transcendental se coloca o mundo dos significados.

O conceito de verdade como velamento e desvelamento aparece como chave para o conceito de mundo. Não é o sujeito que estabelece a relação com o mundo, mas o mundo que estabelece o contexto a partir de cuja compreensão prévia o ser pode acontecer.

egundo Habermas, o discurso filosófico da modernidade se situa no processo de ruptura com a tradição em que gradativamente é superada tanto a metafísica tradicional como o paradigma da consciência, no sentido de um processo de destranscendentalização em que se enfraquece 0 a priori na direção da compreensão de um mundo da vida que se dá como horizonte da comunicação, como estrutura de significados a serem explorados prática e pragmaticamente, em que podem ser postas em discussão as pretensões de racionalidade da operação do mundo, da 
coordenação da ações e da cooperação, com suas exigências de inteligibilidade, de veracidade, de validade e de verdade.

O conceito central da teoria da ação comunicativa de Habermas (1985) mundo da vida e sistema é construído a partir de um contexto heideggeriano e da filosofia da linguagem de Wittgenstein, Austin e Searle.

Concluindo, pode-se afirmar que Habermas não se furta ao enfrentamento da crise da razão na chamada pós-modernidade, que ele percebe como a continuidade do questionamento do próprio conceito e função de uma teoria da racionalidade, alargada para o âmbito não exclusivamente cognitivo, mas para o moral e o estético-expressivo.

O importante é que, rompida a tradição, a consciência da crise da modernidade estilhaça a racionalidade. Nietzsche e Heidegger empreendem a recuperação da metafísica, num plano onde existe apenas o homem e sua forma de existir. Wittgenstein e Adorno optam pelos caminhos da não-realização da filosofia. Marx, Darwin e Freud exercem influência sobre a consciência da época sem a mediação da filosofia. Foucault opta pela desconstrução histórico- sociológica do poder, negando a reflexão filosófica, mas ao mesmo tempo afirmando-a ao constituir o próprio poder como lugar transcendental de sua crítica radical.

Contemporaneamente, as formas de adeus à razão (Feyerabend, 1991) se objetivam na metáfora do navegar nas redes de informação (Lyotard, 1989), no poder de troca e armazenamento da própria informação, no relativismo das visões de mundo e dos jogos de linguagem, em seu esforço de legitimação. Tudo isso indica que a pós-modernidade se cindiu em processos de modernização científico-tecnológicos e processos de autocrítica da razão e das manifestações de racionalidade da ação em diversos contextos de legitimação.

Diante deste imenso cisma que decretou o fim do conceito de razão, o fim das ideologias, é possível reencontrar o rumo da racionalidade, é possivel reconstruir alguma forma de utopia? É possivel superar reducionismos e totalitarismos?

Habermas aponta como possibilidade não a ruptura total com a razão moderna. Apresenta uma proposta procedural para correção da razão moderna, perdida nas múltiplas posições da pós-modernidade. Seu paradigma de trabalho mundo da vida e sistema significa uma tentativa de articular uma reconstrução do conceito de mundo da vida, destranscendentalizado pelas críticas heideggerianas ao formalismo transcendental da fenomenologia husserliana, com a objetividade da racionalidade cognitiva dos sistemas naturais e sociais.

O trabalho simultâneo e integrado entre mundo da vida e sistema pretende criticar a racionalidade instrumental objetivante do sistema, invasiva do mundo da vida, pela fluidificação comunicativa e crítico- discursiva das diferentes esferas do próprio mundo da vida, o qual enquanto horizonte e condição de possibilidade da comunicação é freqüentemente ameaçado pela burocratização e colonização, provocadas pela influência sistêmica. Habermas, nessa tentativa, não cede nem ao objetivismo positivista, nem ao historicismo, nem tampouco ao puro transcendentalismo.

Habermas usa a crítica de Schelling a Hegel, no sentido do abandono da abstração da idéia e volta à existência. Valoriza o conceito de mundo da vida, despido de sua formalidade pela hermenêutica existencial de Heidegger, já urbanizada pela 
hermenêutica gadameriana. Por outro lado, associa a hermenêutica às críticas ao objetivismo positivista e à filosofia da linguagem, integrando as contribuições do último Wittgenstein, de Austin e Searle ao seu conceito de racionalidade discursiva e comunicativa.

Entretanto, não abandona a ambição hegeliano-marxista de uma gênese histórico-crítica da evolução social. Tenta enfrentar esta tarefa aproximando a filosofia das chamadas ciências sociais reconstrutivas (psicanálise, lingüistica, epistemologia genética de Piaget e teoria do desenvolvimento moral de Kohlberg, sociologias compreensiva e crítica) por meio das quais estão em jogo a estrutura de certas aprendizagens básicas da espécie humana.

Apesar de Habermas reconhecer o relativismo das formas de vida, sua aceitação da diferença não implica em incompatibilidade e incomunicabilidade.

Ao reconhecer uma intersubjetividade que se descobre operando num mundo, Habermas pensa poder trabalhar com um procedimento mínimo racional que parte da incondicionalidade de uma ação que busca o entendimento, baseada nas melhores razões e na ausência de dominação. Por outro lado, a idéia de uma condição universal de comunicação e compreensão mútuas, conferindo aos sujeitos a possibilidade de, ao se colocarem como participantes de uma comunicação, situaremse, performativamente, na posição de falante, ouvinte e participante reflexivo, sempre na busca das melhores razões, alargar-se para a construção de um princípio procedural e ético, relativo ao direito e ao dever de participar do discurso.

Desta forma, o filosofar habermasiano não pretende ser mais uma metanarrativa, no estilo da filosofia da consciência que adota um papel reflexivo de observadora privilegiada da racionalidade, mas sim o de um participante de uma discussão em que se busca uma solução teórica por meio de uma recomendação prática, ou seja, que se deve atuar sob a pressuposição do poder unificador da razão comunicativa.

Habermas tem recebido críticas, tanto pelo formalismo de sua teoria da ação comunicativa, como pelo universalismo e ausência de consideração das questões relativas à vida boa, bem como da ameaça do terror prático, presente em sua ética discursiva. Tugendhat (1993) e Loparic (1989) consideram sua ética discursiva, sintetizada nos princípios $(\mathrm{U})$ - de que as normas válidas têm que ser aceitas por todos sem exceção, a não ser a do melhor argumento - e (D) - de que a aceitação depende da participação de todos os envolvidos no discurso prático (Habermas, 1989), acaba abstraída dos contextos específicos que dificultam uma participação isenta de dominação.

Segundo Loparic (1989), mesmo se (U) oferecesse um critério efetivo de decisão para as normas, numa situação de argumentação, isto é, nas condições enumeradas em (D), ele não permitiria justificar a aceitação de (D). Por outro lado, Tugendhat afirma que a questão da fundamentação tem que ser separada da questão da justificação. Para ele Habermas não separa estes planos, acabando por confundir a esfera moral com a política.

Habermas contra-argumenta que o que de fato se exprime na validez deôntica é a autoridade de uma vontade universal, partilhada por todos os interessados, tendo esta despido a qualidade imperativa e assumido uma qualidade moral porque 
apela a um interesse universal que se pode constatar discursivamente e apreender cognitivamente, discernido na perspectiva do participante.

Habermas aceita essas críticas de necessidade de busca de mediações e, como intelectual responsável pelas questões do seu tempo, não tem se furtado ao debate e às reformulações, mas antes tem estimulado em suas incontáveis intervenções e em sua extensa produção acadêmica, como em entrevistas concedidas à imprensa, o apelo para o desenvolvimento de iniciativas democráticas de organização e esclarecimento de grupos que buscam sua emancipação.

A extensa obra de Habermas critica, mas reconstrói as duas vigas mestras da modernidade ocidental: Kant e Hegel. Essas duas vertentes passam na extensa obra habermasiana pelo crivo da crítica ao positivismo, pela hermenêutica existencial de Heidegger, pela crítica ao poder e às ideologias, pela transformação lingüística da filosofia, além da discussão do novo papel articulador entre ciências sociais e filosofia, no sentido não só do questionamento filosófico cognitivo, mas de uma filosofia da ação pós-moderna. Esta elaborada em termos de uma pragmática universal e de uma ética mínima com conseqüências para uma Filosofia do Direito, considera o trânsito teoria e prática, a relação entre justiça e vida boa, arte e vida como desafios a uma aspiração, nunca esgotada de uma racionalidade que se afirma pós-moderna, porque se expressa em múltiplas configurações, mas que insiste em manter sua atitude crítica e uma proposta de recomposição, ainda que provisória, de uma totalidade ética.

\section{Referências bibliográficas}

ADORNO, T., HORKHEIMER, M. Dialética do esclarecimento. Rio de Janeiro: Zahar, 1985.

BERNSTEIN, Richard et al. Habermas y la modernidad. Madrid: Cátedra, 1994.

FEYERABEND, P. Adeus à razão. Lisboa: Edições 70, 1991.

HABERMAS, J. O discurso filosófico da modernidade. Lisboa: Dom Quixote, 1990.

- The theory of communicative action. Boston: Beacon Press, 1985. $2 \mathrm{v}$.

- Consciência moral e agir comunicativo. Rio de Janeiro: Tempo Brasileiro, 1989.

— . O pensamento pós-metafisico. Rio de Janeiro: Tempo Brasileiro, 1990.

—_ Escritos sobre moralidad y eticidad. Buenos Aires: Paidós, 1991.

- Passado como futuro. Rio de Janeiro: Tempo Brasileiro, 1993.

LOPARIC, Zeljko. Habermas e o terror prático. Universidade Estadual de Campinas, 1989.

LYOTARD, J.F. O pós-moderno. Rio de Janeiro: José Olimpio, 1988.

STEIN, Ernildo. Epistemologia e critica da modernidade. Ijuí: Ed. UNIJUI, 1991.

- Seis estudos sobre ser e tempo. Petrópolis: Vozes, 1988.

THOMPSON, John B.; HELD, David. Habermas critical debates. London: MacMillan Press, 1982.

TUGENDHAT, E. Lições sobre ética. Porto Alegre, 1993. 